\title{
THE NEW INCDMTM RESEARCH CENTER FOR INTELLIGENT MECHATRONIC SYSTEMS USED FOR SECURING OBJECTIVES AND INTERVENTION
}

\author{
Gheorghe Silviu Ionut ${ }^{1}$, Negrea Catalin Stefan ${ }^{1}$, Robert Mangher ${ }^{2}$, Vlad Mangher ${ }^{3}$ \\ ${ }^{1}$ INCDMTM - Bucharest \\ ${ }^{2}$ S.C. MDM Standard S.R.L. \\ ${ }^{3}$ Faculty of Mechatronics, University "Politehnica" of Bucharest \\ Emails: silviu1_silviu1@yahoo.com, catalin.negrea95@gmail.com, robert mangher@mdmstandard.ro, \\ vlad robert01@yahoo.com
}

\begin{abstract}
CERMISO is a research and development center focused on optimizing technical and economic solutions for the configuration and utilisation of equipment such as the intelligent autonomous mini-system with air displacement (MIADA) in our country. Result of a finished project of INCDMTM Bucharest it will help to increase the capacity and performance of INCDMTM in international cooperation R\&D projects.

$\mathrm{R} \& \mathrm{D}$ focused efforts are be made on the following directions:

a) Autonomous intelligent mechatronic systems integration in the security space and the environment.

b) Optimizing airborne autonomous intelligent mechatronic systems

c) Secure data transmission technologies

d) Developing micro multi-sensor systems controlled by artificial intelligence.

e) The development of artificial intelligence, automatic data processing in order to prevent disasters and accidents.

f) Developing solutions and anti-hacking security algorithms for autonomous airborne systems.

g) Hardware and software solutions to optimize energy consumption and increase endurance and flight autonomy of airborne mechatronic systems.

The complexity and universality of the CERMISO Center is accomplished by integrating researchers in mechatronics, electronics, computer sciences, precision engineering and aerospace. The R\&D results obtained are further addressed for related industries enabling effective performance of similar equipment in our country. As a vision of R\&D stage we later see enormous possibilities for developing these systems for all existing domains.
\end{abstract}

Keywords: Drone Research and Development, UAV, RPA, ROA, RPV, Artificial Intelligence.

\section{Introduction}

\section{Brief History}

Drones, also known as unmanned aerial vehicles (UAV), are pilotless and non-crewed aircraft that are capable of flight either by remote control or through the use of on-board computers. Other names for these types of aircraft are remotely piloted vehicle (RPV), remotely piloted aircraft (RPA), and remotely operated aircraft (ROA). Drones are commonly used by the military, but are also being implemented in search and rescue operations and being utilized in other civil applications, such as policing and firefighting.

The technology is also an opportunity for hobbyists and other enthusiasts to become skilled drone operators, albeit on a relatively smaller scale. A drone is capable of controlled, sustained level flight and is powered by a jet, reciprocating, or electric engine. UAVs differ from cruise missiles in that drones are recovered after a mission is complete while a cruise missile is destroyed upon impact with its target. Military UAVs may carry and fire munitions, while a cruise missile is a type of munition itself.

The concept of unmanned aerial flight is not a new one. The idea first came to light on August 22, 1849, when Austria attacked the Italian city of Venice with unmanned balloons that were loaded with explosives. Some balloons were launched from the Austrian ship Vulcano. While some balloons reached their intended targets, most were caught in change winds and were blown back over Austrian 
lines. The system was under development for months and an account of the country's plan appeared in an article in a Vienna newspaper at the time:

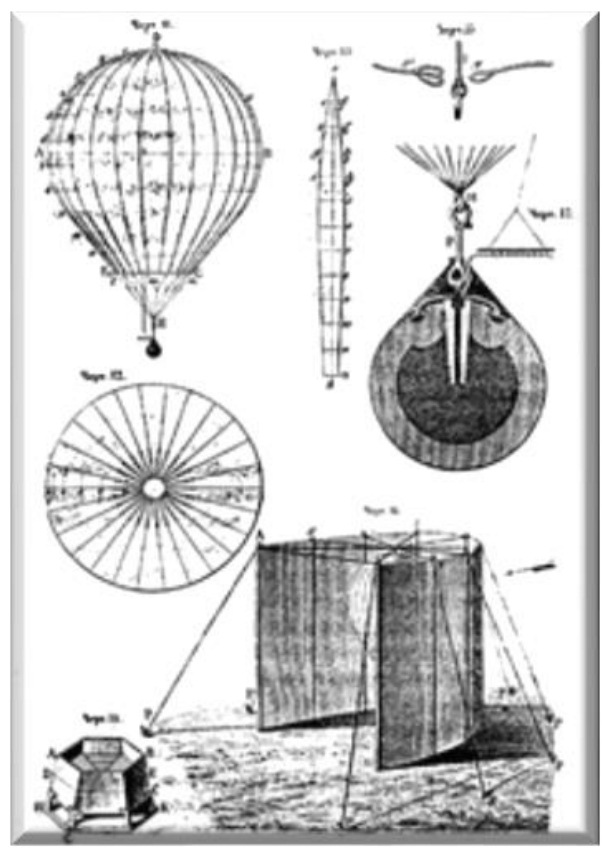

Figure1: The precursors of modern drones were built and used in 1849 to attack Venice

The precursors of modern drones were built and used in 1849 to attack Venice "Venice is to be bombarded by balloons, as the lagoons prevent the approach of artillery. Five balloons, each twentythree feet in diameter, are in construction at Treviso. In a favorable wind the balloons will be launched and directed as near to Venice as possible, and on their being brought to vertical positions over the town, they will be fired by electro magnetism by means of a long-isolated copper wire with a large galvanic battery placed on a building. The bomb falls perpendicularly, and explodes on reaching the ground."

While these early drones do not generally meet today's definition of a UAV, the concept was strong enough that once winged aircraft had been invented, the concept was still alive and kicking and would soon be implemented once again.

\section{World War's}

The first pilotless aircraft were developed during and shortly after World War I. The first was the "Aerial Target," developed in 1916. It was intended to take down Zeppelins, but never flew.
Shortly later, the Hewitt-Sperry Automatic Airplane (the flying bomb) made its maiden flight, demonstrating the concept of unmanned aircraft.

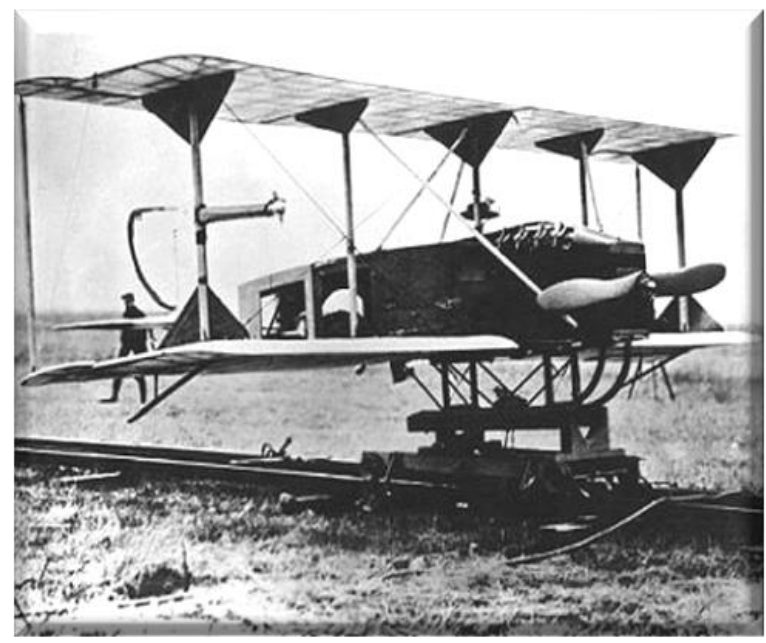

Fig. 2 The Hewitt-Sperry Automatic Airplane was a project undertaken during World War I to develop an aerial torpedo, also called a flying bomb or pilotless aircraft, capable of carrying explosives to its target. It is considered by some to be a precursor of the cruise missile.

This UAV was intended for use as an aerial torpedo, an early version of modern cruise missiles. Control of these aircraft was achieved using gyroscopes. In November 1917, the Automatic Airplane was demonstrated for the US Army. Upon the success of this demonstration, the Army commissioned a project to build an aerial torpedo, which became known as the Kettering Bug and flew in 1918. While the technology was a success, it wasn't in time to fight during wartime, which ended before the UAV could be developed and deployed. Several successors were developed during the period after WWI and prior to WWII.

These included the Larynx, tested by the Royal Navy between 1927 and 1929; the radio-controlled Fairy "Queen" developed by the British in 1931; and the British follow-up UAV "DH.82B Queen Bee" in 1935. Also following on the earlier work by the Army, the US Navy continued to advance UAV technology, experimenting with radio-controlled aircraft. In 1936, the term "drone" was first coined, as the head of the Navy's research group used it to describe radio-controlled aerial targets. During the technology rush of WWII, drones were used both as training tools for antiaircraft gunners and for aerial attack missions. Nazi Germany also had produced and used various UAVs during the course of WWII. 


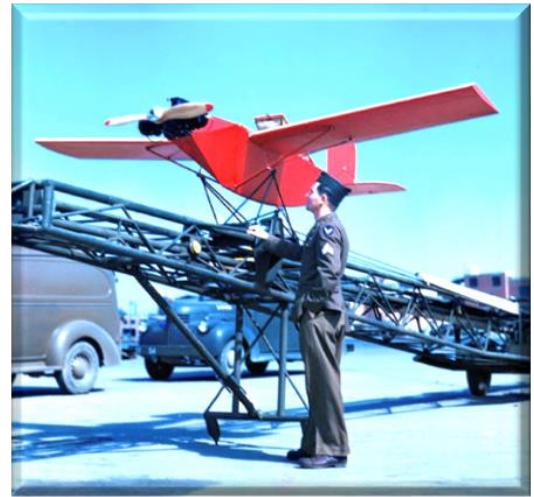

Figure 3: Reginald Denny sells 15,000 radio-controlled target drones to the U.S. military to train anti-aircraft gunners for World War II

After the war, jet engines were applied to drones, with the first being the Teledyne Ryan Firebee I of 1951. By 1955, the Model 1001, developed by Beechcraft, was developed for the US Navy - these UAVs were nothing more than remote-controlled airplanes until the Vietnam Era.

\section{Modern Era}

The birth of US UAVs began in 1959 when the US Air Force, concerned about losing pilots over hostile territory, began planning for unmanned flights. Following a Soviet Union shoot down of the secret "U-2" aircraft in 1960, the highly classified UAV program was launched under the code name "Red Wagon."

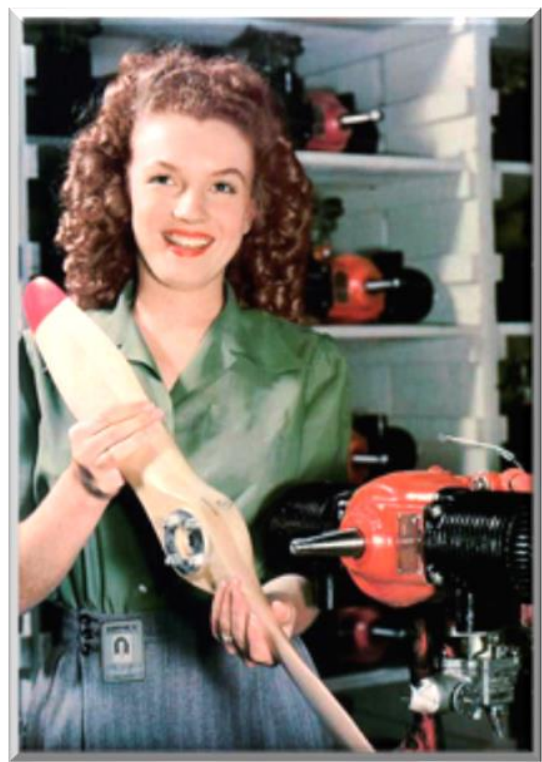

Figure 4: Norma Jeane Dougherty-soon to be known as Marilyn Monroe-working at a wartime assembly plant. On her workbench: a half-assembled drone.

Modern-era UAVs got their first use during the Aug 2 and Aug 4, 1964 clash in the Tonkin Gulf between the US and North Vietnamese navies.
During the Vietnam War. After Chinese photographs surfaced of downed US unmanned aircraft during and after the Vietnam War, the official US Air Force response was "no comment." However, by 1973, the US military officially confirmed that they had been utilizing UAV technology in Vietnam, stating that during the war, more than 3,435 UAV missions were flown, of which about 554 were lost in combat. During the 1973 Yom Kippur War, Israel developed the first UAV with real-time surveillance, after Soviet Union surface-to-air missiles used by Egypt and Syria dealt heavy damage to Israel's fighter jets.

The images and radar decoying provided by these UAVs helped Israel to neutralize Syria's air defenses at the start of the 1982 Lebanon War, resulting in no pilots lost. By 1987, Israel had developed proof-ofconcept capabilities in tailless, stealth-based, threedimensional thrust vectoring flight control, jet steering UAVs for the first time. Interest in UAV technology grew during the 1980s and 1990s - being used during the Persian Gulf War in 1991 - and became cheaper and more capable fighting machines.

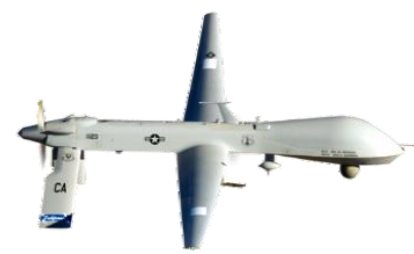

Figure 5: 1995- The General Atomics MQ-1 Predator UAV enters service. In the decade following 9/11, the

Predator will become the public face of drones.

While most drones of the earlier years were primarily surveillance aircrafts, some carried munitions. The General Atomics MQ-1, which utilized an AGM-114 Hellfire air-to-ground missile, was known as an unmanned combat aerial vehicle (UCAV). While most UAVs were utilized by the military, the technology was commissioned by the CIA after the September 11, 2001 terrorist attacks. Intelligence gathering operations began in 2004, with CIA-operated UAVs primarily flown over Afghanistan, Pakistan, Yemen, and Somalia. The CIA's first UAV program was called the Eagle Program.

As of 2008, The USAF has employed 5,331 UAVs, which is twice the number of manned planes. Of these, the Predators have been the most commendable. Unlike other UAVs, the Predator was armed with Hellfire missiles.

The Predators were used during the hunt for Osama Bin Laden and have demonstrated the capability of pointing lasers at targets for pinpoint accuracy. The overall success of the Predator missions is apparent because from June 2005 to June 2006 alone, Predators carried out 2,073 successful missions in 
242 separate raids. While Predator is remotely operated via satellites from more than 7,500 miles away, the Global Hawk operates virtually autonomously. Once the user pushes a button, alerting the UAV to take off, the only interaction between ground and the UAV is directional instructions via GPS. Global Hawks have the ability to take off from San Francisco, fly across the US, and map out the entire state of Maine before having to return. In February 2013, it was reported that UAVs were used by at least 50 countries, several of which have made their own, including Iran, Israel and China. Recently, UAVs are becoming increasingly popular in the commercial and private market. Amazon.com, the largest online retailer, said in December 2013 that it was developing drone technology to one day deliver mail autonomously. Drones are also being developed for hobbyists and other enthusiasts. In reality, these types of aircraft have been common since the 1930s, when Reginald Denny mass-produced the first radio-controlled aircraft for the hobby market. While RC airplanes remained popular through the decades, recent technology is now making them smaller, more powerful and more useful - some adding cameras and GPS trackers, as well as making them more affordable for everyday enthusiasts.

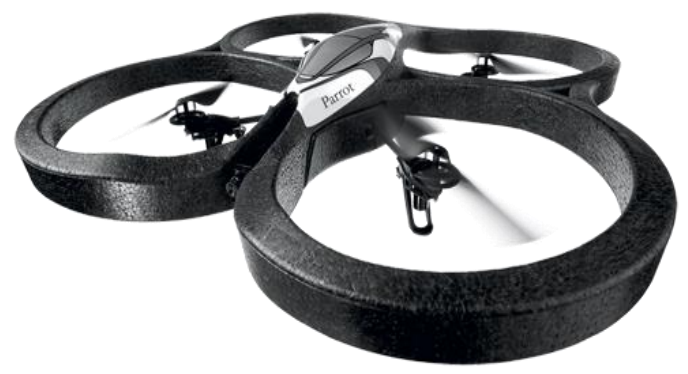

Figure 6: The Parrot AR Drone, a smartphonecontrolled quadcopter for consumers, is introduced at the Consumer Electronics Show in Las Vegas in 2010

The modern technologies make the evolution of drones to be almost unpredictable as long as small firms are already developing human caring versions as VC 200 vobocopter:

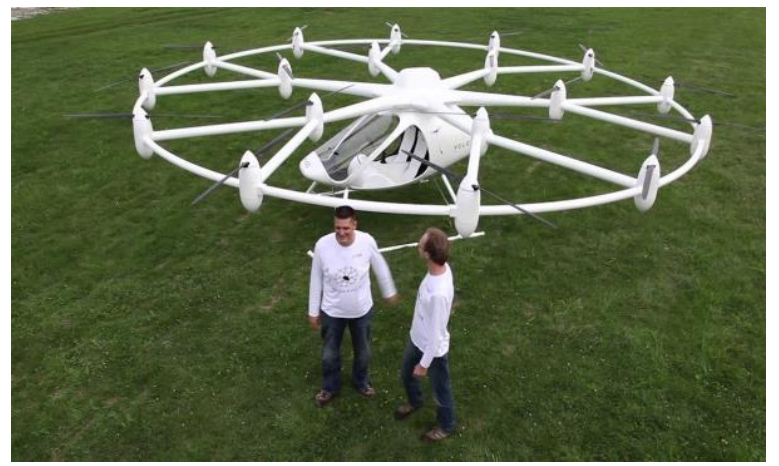

Also in security and rapid interventions processes small but powerful drones can make the difference between life and death. In disaster cases, the UAV interventions is extremely useful and gives to the operators the opportunity to access large areas for searching objectives, human survivors or perimeter security assurance. Almost infinite possibilities for using UAVs, arise from the technological advancement. Using drones in rapid interventions means: speed, complex visual information and carrying possibilities, provided by long autonomous capabilities.

Generally it is considered that at present an intervention drone must be capable to reach maximum speeds of over $150 \mathrm{Km} /$ hour, must be able to carry around $20 \mathrm{Kg}$, must have stereovision or at least HD mono visual, and have an autonomy of at least 35 minutes at half maximum speed and $70 \%$ maximum carrying possibilities.

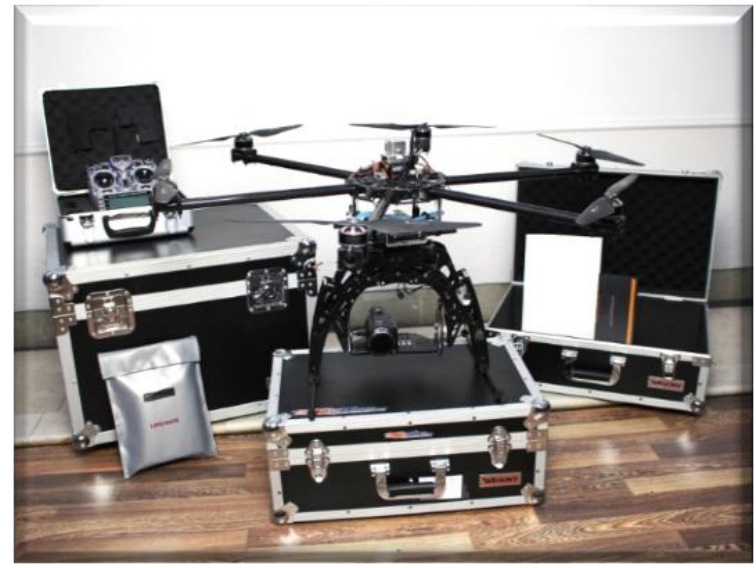

Figure 7: XF-P6 - intervention drone 4,5 kg carrying possibilities, $60 \mathrm{~km} / \mathrm{h}, 35$ minutes autonomy

The remote possibilities must be also taken into account and as the communications between human operator and the drone must be in real time at least in "seek and find" operations. Other secondary functions, extremely useful can also be: predefined missions without human control, return home functions triggered by various real time situations (battery loss, connection loss, etc.).

Taking into account the actual and future development of UAVs, our institute has finalized a complex project to create a center with research facilities (CERMISO) in the optimization of Autonomous Intelligent Airborne Mini-system (MIADA) with direct applications in safety and security objectives and intervention in case of disasters in difficult areas to reach. The project consists in setting up a research center for intelligent mechatronic autonomous airborne systems will have a large range of utility in securing rapid and effective objectives and interventions in all areas where access is difficult or would directly endanger the 
safety of operators. R\&D Laboratory will be located within the premises INCDMTM of Sos. Pantelimon, Nr. 6-8, Sector 2, Bucharest. Basically center activity will be conducted on the following R\&D guidelines:

1-Autonomous intelligent mechatronic systems integration in the security space and the environment.

2-Airborne autonomous intelligent mechatronic systems Optimization

3-Secure data transmission technology

4-Developing micro multisensory systems controlled by artificial intelligence.

5-The development of artificial intelligence for automatic data processing in order to prevent disasters and accidents.

6-Developing solutions and anti-hacking security algorithms for autonomous airborne systems.

7-Hardware and software solutions to optimize energy consumption and increase endurance and autonomy of airborne mechatronic systems.

The Proposed objectives of the CERMISO Center are:

1. The implication of the INCDMTM research Center in European projects especially $\mathrm{H} 2020$;

2. The achievement of the capacity to develop partnerships with economic agents interested in thematic research and the construction of functional models or prototypes in the project field;

3. The achievement of the capacity to develop partnerships with universities, engaging students in educational activities and attracting young researchers from among the latter by providing the research center with demonstration, testing or research equipment;

4. INCDMTM affiliation by means of the research Center to the new European platforms.

Results will be made available to companies having manufacture and production possibilities for MIADA equipment types, considering that there are all the necessary conditions to obtain ultra-high performance equipment in our country. At this moment in Romania there is no such equipment, in study or in the research stage. The range of use of Autonomous Intelligent Airborne Mini-system (MIADA) type is extremely broad, covering all the major existing fields just by a reconfigurable modular concept per task/intended use as it is addressed in the CERMISO concept.

\section{Novelty Involved}

The great novelty of this proposed system consists in absolute mobility access to the location, speed response in intervention, artificial intelligence allowing quick decision making and transmitting all relevant information to the operator, in real time.

It is worth mentioning as a novelty the antihacking system and self-homecoming in extreme cases (lack of energy, lack of communication signal, interference, etc.)

Such studies and research in this area will bring a high degree of novelty in Europe and worldwide. Nationally the novelty becomes much greater and opens new opportunities both in the production and services as there are directly generated and interconnected.

We can address the integration of the R\&D activity in national and international networks on this topic, knowing that at the moment this area is booming and in an early phase, including in Europe, which will also allow Romanian specialists to bring a real and valuable contribution to the progress in implementing such equipment in the very near future. A united Europe needs to ensure territorial peace and security in these periods context in which problems still appear at the Union's borders. At a time when borders are targets for a large number of immigrants who desire a safer and better life violates the European standards of travel and undesirable events, but unfortunately occur independently of the will of the European Union such as accidents from the atomic power plant in Bulgaria, Chernobyl, and even the current conflict in Ukraine, require new ways of securing both the territorial security and the safety of the residents of Member States.

The European environment security policy concluded that it is better to prevent than to tackle a disastrous event. And just that is what can be done with such aerial surveillance systems by rapidly identifying signs of danger before the actual outbreak of the event, through rapid and precise measurements but especially without endangering lives.

In the near future formation of such equipment could form a living shield against unwanted events and situations from the most areas existing in daily life.

Thus, will be addressed new domains and solutions for surveillance, security and intervention, the areas of possible uses increasing more and more.

Possibility of manufacture of such equipment in our country opens their broad market opportunities both in our country and abroad. There will be opportunities for cooperation including in the field of European manufacturers, in view of the possibility of optimizing production costs and components quality. The results correlated with optimization solutions will train in the production process of both small enterprises and medium ones creating new fields and even concepts and new standards, not only in security and intervention but also in other areas, where applications could be found for such equipment.

Moreover, the involvement of the MECHATREC Cluster (which includes INCDMTM) is already present through the partnership agreements already 
concluded for this area and supporting the CERMISO center, was provided with great enthusiasm, sensing the future offered by this partnership. This provides the first platform to launch MIADA equipment on Romanian and European market, as a result of the R\&D activity that will be held in CERMISO center. The center will be supported unconditionally by the MECHATREC cluster members, both during the project implementation period and in subsequent research and development period.

Moreover, in the CERMISO center, activities will be continued on the research and development of this equipment on other fields, as each new approach to a user configuration can create new and novel approaches to other areas of interest, starting from the civil use of "hobby" type to the military use.

Such studies and research in this area will bring a high degree of novelty in Europe and worldwide. Nationally the novelty provides a much greater range and opens new opportunities both in the production and services provided by such an equipment as there are indirectly generated by the usage of it.

\section{Beneficiaries}

Beneficiaries are, in the first stage, from the areas dedicated to the objectives security and interventions in disaster cases. But in a second phase, possible very shortly, the number of beneficiaries grows rapidly covering areas such as health, transport, agriculture, power engineering, hydraulic engineering, forestry, education and academia. Clearly the big advantage of this system is the fact that as the equipment conquers new fields of use, the more new applications are discovered.

In accordance with the "2014-2020 Operational Program Competitiveness" project contributed to the development of several areas of smart specialization: - Information and communication technologies, space and security - Information and communication technologies and Space through research and development of new informatics products dedicated surveillance equipment to areas of interest, crossborder and other areas with high security

- Security - innovative methods and technologies to combat cross-border terrorism, organized crime, illegal trafficking of goods and people through research and development of new surveillance equipment to areas of interest, cross-border and other areas with high security

- Bio economy - Monitoring cross-border spread of highly pathogenic microorganisms and the possibility of monitoring the agro-food crops through possibility of monitoring the agro-food crops through research and development of crop and traffic lanes surveillance equipment

- Energy, environment and climate change Management of risk induced by climate change on resources through research and development of surveillance equipment for climatic factors using modern energy saving technologies

- Eco-Nano-material technologies and advanced materials - New generations of vehicles, green technologies and energy efficient through research and development of modern equipment with low energy consumption using modern technologies

- Health - Healthy aging, lifestyle and public health and Therapy personalized / group and therapeutic monitoring through research and development of equipment for medical surveillance, provisioning, disaster intervention, surveillance and supply to isolated people.

In conclusion we consider it is an area of great future and that it is practically at the beginning, it encourages us to believe that the establishment of the CERMISO center attaches great chance to Romanian engineering and research to start a race to implement technologies, just not very modern but with a great future, and can develop, shoulder to shoulder, with scientists and engineers in highly developed countries in Europe and worldwide.

The project results are primarily devoted, as could be seen from the description of research and development activities described above, to the information technologies and communications, space and security. Unification UAV and RPA concepts in one equipment MIADA type endowed with artificial intelligence, fits with great success in the integrated space applications generates a new product with wide range of applicability for all domains. The new concept proposed for the surveillance with MIADA type equipment, organized in flying formation, fully autonomous and selfpowered, without disruption of security itself, can make a real revolution in methodology and innovative technology in combating cross-border terrorism, organized crime, trafficking illegal goods and people. This is because large areas can be monitored $24 / 7$, with a relatively small number of devices that require no operator intervention apart from cases where intrusion is detected.

MIADA equipment can monitor vast areas of cross-border transmitting a real-time flow of images of 20 frames / second in high definition to operational headquarters. Meanwhile Artificial Intelligence analyzes the video information and in the case of motion detection the operator screen will be marked with a Rectangle framing the moving parts. The movement detection will be signaled with audible alarm to operational headquarters, to draw attention to operator. All the information can be video archived to dedicated media in operational headquarters so the history of the scanning of the cross-border area can be accessed for later use. It is expected an increased border security for the location scanned by MIADA equipment, both during the day and at night. Video sensory systems and 
other adjacent sensors will work also in infrared light (even if the Infrared images will be captured in black / white, it will be a HD definition). So it will be possible for a single operator to monitor vast border areas, in real time, dynamic and very precise, any unauthorized crossing being intercepted instantly. As it was mentioned above, we highlight the absolute novelty of this R\&D activity both in our country and in other European countries.

\section{Why MIADA?}

The efficiency of MIADA type equipment in difficult working conditions, adaptability to functions of parameters scan viewing and performance in real time focuses using them with great success on air and ground security. So with low costs of production and a wide range of possibilities for data acquisition and processing, these devices can have a decisive role in prevention but also in solving problems arising from disasters, whether natural, technological, or human error type. The research focus will go towards equipment with larger port, autonomy and reconfigurable. Research and development in this field does not yet exist in our country, there are only three of its kind in endowment of MAPN (USA import) and the rest just small versions "hobby" type for the general public.

A summary of some of the possible uses, identifiable at least at this level of the beginning of this kind of equipment, as evidenced in research and testing studies that began about two years in some industrial nations such as the USA, Italy, France England and Germany.

Thus, in case of disasters and accidents in areas difficult to access the scanning and identifying the targets or locations can be made using this equipment individually or in group depending on the severity and speed of response needed to identify and intervention. The total accessibility of this equipment makes them irreplaceable where access is hampered by various geographical factors existing. Access with supply of vital resources such as medicines, food and water in disaster areas (e.g. remote villages impossible to access by land until the end of snow removal from the access roads) can be done quickly by air within a few meters precision from destination, saving lives until the intervention and rescue teams can reach the scene calamity.

Determination of problems arising in such situations, including in other type of large area fires, floods, explosions etc., can be done quickly, with great detail both video and positional. The wide multiple sensors dedicated to measurements enlarge the database collected in real-time on-site, helping enormously in developing a plan more appropriate to the problem detected at the location. Here we expect also the possibility of sourcing services for elderly people with walking problems requiring support and medical supervision. Multiple services for control and inspection of large or small industrial parks, factories and large industries with degree of danger such as refining, chemical industry etc. where production equipment can be inspected continuously to detect early any problems of failures, before a disaster occurs. Thermal Scan, one of the functions implemented on such MIADA type equipment can identify problems in both pressure installations and electrical circuits existing in the field. The same equipment can nondestructively inspect, complete and extremely fast large structures from buildings to dams.

We expect the use of such equipment also in health, transport, agriculture, power engineering, hydraulic engineering, forestry, education and academia. The systems generate new services modern and innovative type, some of them being the key in this time, in trial and testing phase, in rich countries. Large corporations such as Google and Amazon are studying the possibility of home delivery of goods by air with low cost and high response speeds. Thus, from shopping to supplying products intended to save human lives, that will be available on this communication channel, having extremely short times for delivery. In our country one of the main users and beneficiaries of the services provided by such equipment is agriculture, one of the areas that recently experienced a strong growth and development so determining the stage of crops of any kind by air scanning and mapping becomes mandatory for growth efficiency in the field. More reducing the intake of chemicals adjacent, such as chemical fertilizers, herbicides and fungicides, is fundamentally associated with the enormous amount of data that can be measured quickly at a complex video and parameters scanning (multiplicity of factors measured are determined only by the types of sensors that can be mounted on MIADA equipment). Forestry in turn can benefit from a large increase of both production efficiency and proper security and control against vandalism. No less important the use of MIADA equipment individually or in formations for any large areas security and utility of any type of interstate borders.

The range of users and possibilities of such equipment are continuously growing so most likely it will almost completely cover both the private and industrial area.

\section{Why CERMISO?}

CERMISO Center activities will be mainly aimed at optimizing their technical and economic solutions for the generation, configuration and utilization of the equipment such as intelligent autonomous minisystem with air displacement (MIADA) type in our country. 
Project financing helped to increase the capacity and performance of INCDMTM in international cooperation in R\&D.

R\&D's concentration efforts will be made on following directions:

a) Autonomous intelligent mechatronic systems integration in the security space and the environment.

A study was done for the optimal place of the systems type MIADA in the security space and the environment to determine the manner in which you can use, how they should be configured from constructively point of view and artificial intelligence point of view, and other possible applications for adjustments required by future users. It has made the basis of an open multiconfigurable structure, starting from a basic system that can be adapted with minimum effort and time in any desired configuration per application.

b) Optimizing airborne autonomous intelligent mechatronic systems

It studied how subassemblies and parts of a type MIADA system can be optimized by using miniaturization mechatronic type. It considered increasing the mechanical strength, propulsion system reconfiguration, all in the context of shrinking transport weight and weight increase over $1 / 5$ of the equipment MIADA

c) Secure data transmission technology

Data packets transmitted wirelessly by $\mathrm{RF}$, so the command MIADA and those containing the data itself is made collections of equipment must be transmitted on secured channels of information, encrypted unique and access to them can be made strict equipment operator. They will study and implement encryption algorithms very high for both types of signal.

d) Developing micro multisensory systems controlled by artificial intelligence.

Because we need a quick and universal reconfigurable system covering all desired applications, we studied the possibility of installing a sensor as large variety to cover all data in one unit. Such type systems are designed as interchangeable mechanical grippers so that element and sensor type, it is most likely controlled by a complex AI already prepared for any configuration.

e) The development of artificial intelligence automatic data processing in order to prevent disasters and accidents.

Artificial intelligence is a large area studied, researched and developed, because its role is extremely complex. Three directions were studied which later were configured in a single unit AI, namely: control the flight manual and flight control automatically collect, process and transmit data collected in flight and system multi-driver to recognize and use any type of sensor It may be mounted. f) Developing solutions and anti-hacking security algorithms for autonomous airborne systems.

To secure MIADA against diversion system's physical methods hacking research should be unique algorithms, undecipherable control and the existence of protocols for safety where orders are scrambled in order to embezzle. There were be studies to find solutions and safe auto guidance in the context of all possibilities jamming possible so that in case of real danger for the System MIADA is to return safely, visual operator and even try (if the configuration allows) identification of all jamming / hacking parameters in order to possible identification of abusers.

g) Hardware and software solutions to optimize energy consumption and increase endurance and flight autonomy of airborne mechatronic systems.

Best solutions have also been studied the in terms of battery capacity and other unconventional energy possible sources, reducing consumption of hardware (but not in power detriment and computing speed necessary) and optimization party software in terms of energy, without impairing the optimal parameters of the artificial intelligence.

Far from exhaustive we are convinced that the approach proposed for the 7 directions will appeal to many subdomains as furthering research in this new field found in an early phase even in super developed countries. The complexity and universality of the R\&D activity integrating researchers in mechatronics, electronics, computer sciences, precision engineering, and aerospace and the results obtained are be further addressed for related industries enabling effective performance of such equipment in our country. As a vision of the R\&D stage, later, we see enormous possibilities for developing these systems for all existing domains, and these will be addressed in a very short time.

\section{References}

[1] Daniel Tal, Jon Altschuld, Drone Technology in Architecture, Engineering and Construction: A Strategic Guide to Unmanned Aerial Vehicle Operation and Implementation, ISBN: 978-1-11954588-0, February 2021

[2] Adam Juniper, The Complete Guide to Drones Extended 2nd Edition, Editor Wellfleet, April 16, 2018

[3] https://www.mdmstandard.ro/ro/ accessed on 15.09.2021

[4] https://topmetrology.ro/ accessed on 15.09.2021

[5] https://gnex.ro/ accessed on 15.09.2021 